\title{
Cytotoxicity and genotoxicity in liver cells induced by cobalt nanoparticles and ions
}

\section{Y. K. Liu, X. X. Deng, H.L. Yang}

The Affiliated Hospital to Soochow University, Jiangsu, China

= Y. K. Liu, MD, Attending Physician,

- H.L. Yang, PhD, Professor, Department of Orthopaedics, The Affiliated Hospital to Soochow University, Jiangsu, China. - X. X. Deng, MD, Student, The Affiliated Hospital to Nantong University, Jiangsu, China.

Correspondence should be sent to Dr H. L. Yang; email: yanghuilin912@163.com

doi: 10.1302/2046-3758.510 BJR-2016-0016.R1

Bone Joint Res 2016;5:461-469. Received: 31 January 2016; Accepted: 4 July 2016

\section{Objectives}

The cytotoxicity induced by cobalt ions $\left(\mathrm{Co}^{2+}\right)$ and cobalt nanoparticles (Co-NPs) which released following the insertion of a total hip prosthesis, has been reported. However, little is known about the underlying mechanisms. In this study, we investigate the toxic effect of $\mathrm{Co}^{2+}$ and Co-NPs on liver cells, and explain further the potential mechanisms.

\section{Methods}

Co-NPs were characterised for size, shape, elemental analysis, and hydrodynamic diameter, and were assessed by Transmission Electron Microscope, Scanning Electron Microscope, Energy Dispersive X-ray Spectroscopy and Dynamic Light Scattering. BRL-3A cells were used in this study. Cytotoxicity was evaluated by MTT and lactate dehydrogenase release assay. In order to clarify the potential mechanisms, reactive oxygen species, Bax/Bcl-2 mRNA expression, IL-8 mRNA expression and DNA damage were assessed on BRL-3A cells after $\mathrm{Co}^{2+}$ or $\mathrm{Co}-\mathrm{NPs}$ treatment.

\section{Results}

Results showed cytotoxic effects of $\mathrm{Co}^{2+}$ and $\mathrm{Co}-\mathrm{NPs}$ were dependent upon time and dosage, and the cytotoxicity of Co-NPs was greater than that of $\mathrm{Co}^{2+}$. In addition, Co-NPs elicited a significant $(p<0.05)$ reduction in cell viability with a concomitant increase in lactic dehydrogenase release, reactive oxygen species generation, IL-8 mRNA expression, Bax/Bcl-2 mRNA expression and DNA damage after 24 hours of exposure.

\section{Conclusion}

Co-NPs induced greater cytotoxicity and genotoxicity in BRL-3A cells than $\mathrm{Co}^{2+}$. Cell membrane damage, oxidative stress, immune inflammation and DNA damage may play an important role in the effects of Co-NPs on liver cells.

Cite this article: Bone Joint Res 2016;5:461-469

Keywords: Co-NPs; Cytotoxicity; Oxidative stress; DNA damage

\section{Article focus}

- Cobalt chrome (CoCr) metal-on-metal (MOM) total hip arthroplasties have recently been in clinical use.

- It has been reported that metal debris can incorporate into the periprosthetic tissue or enter the bloodstream.

- The objectives of this study were to evaluate the effects of cobalt ions $\left(\mathrm{Co}^{2+}\right)$ or cobalt nanoparticules (Co-NPs) on liver cells and to clarify the potential mechanisms of these effects.

\section{Key messages}

- Co-NPs induced significantly greater production of intracellular ROS than
$\mathrm{Co}^{2+}$ on normal liver cells after 24 hours of exposure.

- The $\mathrm{Bax} / \mathrm{Bcl}-2$ ratiowas increased dose dependently in BRL-3A cells with $\mathrm{Co}^{2+}$ and Co-NPs treatment.

- Co-NPs may correlate with DNA damage.

\section{Strengths and limitations}

- There were insufficient data available to explain the relation between ROS and the $\mathrm{Bcl}-2$ family, and further studies are necessary to evaluate the relevance between them.

- Future research should focus on clinically relevant experimental research in vivo. 


\section{Introduction}

Cobalt chrome (CoCr) metal-on-metal (MoM) total hip arthroplasties (THA) have been widely used in clinical practice. Compared with metal-on-polyethylene (MoP) bearings, MoM THAs demonstrated lower rates of wear, reducing wear-induced osteolysis as the main cause of loosening of prostheses. ${ }^{1}$ Because of low wear, the prostheses were primarily selected for younger and more active patients. ${ }^{2}$ Whilst numerous studies demonstrated that MoM THAs released a large amount of very small wear particles and metal ions, the number of particles was up to 500 times higher than the MoP bearings. ${ }^{3}$ Particles have been reported to be smaller than $50 \mathrm{~nm}$ in size. ${ }^{4}$ Once the diameter of non-toxic or toxic materials reaches nanoscale, the nature of the biological effects may change. ${ }^{5}$

It has been reported that metal debris can incorporate into the periprosthetic tissue or enter the bloodstream, ${ }^{6}$ and patients may have higher blood cobalt and chromium concentrations than normal. ${ }^{7}$ Metal particles and ions gathered into the periprosthetic tissue may induce inflammatory reactions and create masses of soft-tissue and fluid collections. This could potentially lead to tissue

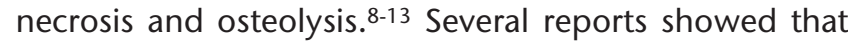
patients with elevated cobalt and/or chromium concentrations in blood, serum or plasma presented serious systemic symptoms including neurological conditions, cardiomyopathy and hypothyroidism. ${ }^{14-21}$

Cobalt ions $\left(\mathrm{Co}^{2+}\right)$ and cobalt nanoparticles (Co-NPs) were identified as the important degradation products of MoM THA. ${ }^{22}$ Recently, the biological effects of CoCr nanoparticles and ions on macrophages demonstrated that only Co-NPs (30 $\mathrm{nm}$ ) exhibited cytotoxicity in vitro relative to Cr-NPs (30 nm). ${ }^{23}$ However, there was a definite lack of information on the toxicity and the mechanisms of $\mathrm{Co}^{2+}$ or Co-NPs on liver cells. Therefore, in this study, we evaluated the effects of $\mathrm{CO}^{2+}$ and Co-NPs on liver cells and attempted to determine the probable potential mechanisms.

\section{Materials and Methods}

Materials. The rat liver cell line, BRL-3A, was obtained from the Shanghai Cell Bank at the Chinese Academy of Sciences. $\mathrm{CoCl}_{2}-6 \mathrm{H}_{2} \mathrm{O}, \mathrm{Co}-\mathrm{NPs}$, dimethyl sulfoxide (DMSO), DCFH-DA (2', 7'-Dichlorofluorescin diacetate), TRIzol and MTT (3-(4, 5-dimethylthiazol-2-yl)-2, 5-diphenyltetrazolium bromide) were obtained from Sigma-Aldrich (St. Louis, Missouri). $\mathrm{Co}^{2+}$ was prepared at a concentration of $10 \mathrm{mM}$ using ultrapure water and sterilised using a $0.22 \mu \mathrm{m}$ filter (Merck Millipore, Darmstadt, Germany). In each experiment, the stock solutions were freshly diluted with a culture medium to the test concentrations. Co-NPs $(30 \mathrm{~nm}$ to70 nm, with a median size of $50 \mathrm{~nm}$ ) samples were heat sterilised $\left(180^{\circ} \mathrm{C}\right.$, four hours) and then suspended in ultrapure water at a concentration of $100 \mathrm{mM}$. The stock solutions were sonicated intermittently six times for two minutes and freshly diluted with a culture medium to the test concentrations. According to other studies 24,25 and our pilot experiments (data not shown), the concentrations of $\mathrm{Co}^{2+}$ and Co-NPs used in this study were $0 \mu \mathrm{M}$ to 500 $\mu \mathrm{M}$. Dulbecco's Modified Eagle's medium (DMEM), fetal bovine serum (FBS), trypsin-EDTA and penicillin/streptomycin were purchased from Invitrogen Ltd (Paisley, United Kingdom). Tissue culture dishes were obtained from Corning Inc. (New York, New York).

Physicochemical characterisation of Co-NPs. Co-NPs were characterised for size, shape and hydrodynamic diameter. The size, microstructure and elemental composition of Co-NPs were assessed by high-resolution scanning electron microscopy (SEM), transmission electron microscopy (TEM) and energy dispersive X-ray spectroscopy (EDS). In brief, Co-NPs were suspended in DMEM supplemented with $5 \%$ FBS at a concentration of one $\mathrm{mg} / \mathrm{mL}$ ( $\mathrm{pH} 7.2$ to 7.4), then the sample was sonicated by using a sonicator bath until a homogeneous suspension formed. A drop of aqueous Co-NPs suspension was placed onto a carbon-coated copper grid and air-dried to obtain SEM and TEM images. EDS was employed for elemental analysis. Dynamic laser light scattering (DLS) measurements were used to determine the hydrodynamic diameter and size distribution of Co nanoparticles in the cell culture medium.

Cell preparation. Frozen BRL-3A cells were thawed, mixed with $10 \mathrm{~mL}$ culture medium, and centrifuged at $1000 \mathrm{rpm} / \mathrm{min}$ for five minutes. The cells were mixed with DMEM supplemented with $10 \%$ FBS and $100 \mathrm{U} / \mathrm{mL}$ penicillin/streptomycin, blended into a single-cell suspension at a concentration of $5 \times 10^{5}$ cells $/ \mathrm{mL}$. Cells were cultured at $37^{\circ} \mathrm{C}$ in a humidified incubator containing $5 \%$ $\mathrm{CO}_{2}$ and $95 \%$ air.

Cell viability assay. The effect of $\mathrm{Co}^{2+}$ and $\mathrm{Co}-\mathrm{NPS}$ on the viability of BRL-3A cells was evaluated using the MTT assay. Briefly, $5 \times 10^{3}$ cells/well were plated into 96-well tissue culture plates and exposed to $\mathrm{Co}^{2+}$ and Co-NPs at varying concentrations $(1 \mu \mathrm{M}, 5 \mu \mathrm{M}, 10 \mu \mathrm{M} 50 \mu \mathrm{M}, 100 \mu \mathrm{M}$ and $500 \mu \mathrm{M}$ ) for four, 24 and 48 hours. Culture medium served as the control in each experiment. Optical density was measured at $570 \mathrm{~nm}$ with a reference wavelength of $630 \mathrm{~nm}$ using a microplate reader. All experiments were performed in triplicate. Cell viability rates were shown as a percentage of the control. The $50 \%$ cytotoxic concentration ( $C_{50}$ value) was then calculated.

Lactose dehydrogenase (LDH) activity. LDH release was used as an indicator of cell membrane damage after 24 hours of exposure to $\mathrm{Co}^{2+}$ or Co-NPs at two concentrations $(10 \mu \mathrm{M}$ and $100 \mu \mathrm{M}), \mathrm{LDH}$ release was measured by an LDH assay kit (Beyotime Biotechnology, Shanghai, China) according to the manufacturer's protocol. The samples were assessed using a spectrophotometer. $0.01 \%$ Triton X-100 treatment for two minutes was used as a positive control. 
Table I. Quantitative real-time polymerase chain reaction primers

\begin{tabular}{lll}
\hline Primer & Forward $\left(\mathbf{5}^{\prime} \mathbf{- 3} \mathbf{3}\right)$ & Reverse $\mathbf{( 5 ^ { \prime } - \mathbf { 3 } ^ { \prime } )}$ \\
\hline BCl-2 & CCGGGAGATCGTGATGAAGT & ATCCCAGCCTCCGTTATCCT \\
Bax & CCAAGAAGCTCGAGCGAGTGTC & TGAGGACTCCAGCCACAAAGA \\
IL-8 & AAGATTGTCCAAAAGATGCTAA & ATCGGTGCAATCTATCTTCTTT \\
GAPDH & GGTATCGTGGAAGGACTCATGAC & ATGCCAGTGAGCTTCCCGTTCAGC \\
\hline
\end{tabular}

Measurement of ROS accumulation. The production of intracellular reactive oxygen species (ROS) was measured by using 2', 7'-Dichlorofluorescin diacetate (DCFH-DA). ${ }^{26}$ DCFH-DA passively enters the cell, where it reacts with ROS to form the highly fluorescent compound 2', 7'dichlorofluorescein. Briefly, $10 \mathrm{mM}$ DCFH-DA stock solution was diluted in culture medium without serum to yield a $10 \mu \mathrm{M}$ working solution. The cells in six-well plates were incubated for 24 hours, and then treated with $\mathrm{Co}^{2+}$ or Co-NPs for 24 hours. The culture medium was then removed and DCFH-DA was added at $37^{\circ} \mathrm{C}$ for 20 minutes. Cells were then washed three times with DMEM and the fluorescence was recorded at $480 \mathrm{~nm} / 525 \mathrm{~nm}$ (excitation/emission) wavelengths. The intensity of fluorescence was measured by a fluorescence plate reader and by laser confocal microscopy. $\mathrm{H}_{2} \mathrm{O}_{2}(100 \mathrm{mM})$ was used as a positive control.

RNA Isolation and quantitative real-time polymerase chain reaction (PCR). Total RNA was extracted from the BRL-3A cells using the Trizol-based method. Approximately one $\mu \mathrm{g}$ of total RNA was reverse-transcribed into first-strand cDNA using RevertAid First Strand cDNA Synthesis Kit (Thermo Fischer Scientific, Waltham, Massachusetts). The synthesised cDNA was used for quantitative realtime PCR and performed using UltraSYBR Mixture (With Rox) (ComWin Biotech Co., Ltd, Beijing, China), then analysed on an ABI 7500 Real-Time PCR System (Applied Biosystems, Foster City, California). All gene expression data are normalised to glyceraldehyde 3-phosphate dehydrogenase (GAPDH) expression levels. The reaction conditions were as follows: initial $94^{\circ} \mathrm{C}$ for 30 seconds, then 35 cycles of $94^{\circ} \mathrm{C}$ for five seconds, $58^{\circ} \mathrm{C}$ for $15 \mathrm{sec}$ onds, $72^{\circ} \mathrm{C}$ for ten seconds, and a final extension at $72^{\circ} \mathrm{C}$ for ten minutes. Specific primers are shown in Table I.

Comet test. Co ${ }^{2+}$ and Co-NPs concentrations $(10 \mu \mathrm{M}$ and $100 \mu \mathrm{M}$ ) below $\mathrm{CC}_{50}$ were selected to evaluate DNA damage in the following alkaline comet assay. The alkaline comet assay for assessment of primary DNA damage was performed according to the method described by Singh et $\mathrm{al}^{27}$ with some modifications. Cells cultured in 24-well plates were exposed to $\mathrm{Co}^{2+}$ and Co-NPs for 24 hours, then washed with phosphate-buffered saline (PBS) and re-suspended in $0.5 \%$ low melting point agarose (LMPA) and located between a layer of $1 \%$ normal melting point agarose (NMPA) and a layer of $0.5 \%$ LMPA on microscope slides. Afterwards, the slides were immersed in cold fresh lysing solution $(2.5 \mathrm{M} \mathrm{NaCl}, 100$ $\mathrm{mM} \mathrm{Na}{ }_{2}$ EDTA, $10 \mathrm{mM}$ Tris, 10\% DMSO, 1\% Triton X-100, and $1 \%$ laurosylsarcosinate, $\mathrm{pH}$ ten) overnight. All procedures were performed under dim light. The next day, slides were incubated at $4^{\circ} \mathrm{C}$ in fresh alkaline buffer $(0.3$ $\mathrm{M} \mathrm{NaOH}$ and $1 \mathrm{mM}$ EDTA, pH 13) for 30 minutes and electrophoresed at $4{ }^{\circ} \mathrm{C}$ for 20 minutes at $0.73 \mathrm{~V} / \mathrm{cm}$ and approximately $300 \mathrm{~mA}$. After electrophoresis, the slides were washed in neutralisation buffer (0.4 M Tris, $\mathrm{pH} 7.5)$, fixed with ethanol for three minutes, stained with propidium iodide $(5 \mu \mathrm{g} / \mathrm{mL})$ and analysed using a fluorescent microscope (Olympus BX50; Olympus Corp., Tokyo, Japan). A total of 100 randomly selected cells were analysed by the CASP software. ${ }^{28}$ DNA damage was evaluated by Olive tail moment and the percentage of DNA in the tail (\%Tail DNA).

Statistical analysis. All experiments were performed in triplicate, and the data are shown as mean and standard deviation (SD) of three separate experiments. All statistical analysis were performed with Graphpad Prism software 5 (La Jolla, California) using one-way analysis of variance (ANOVA) followed by Dunnett's test to evaluate significance relative to control. The probability values of $p<0.05$ were considered significant, and $p<0.01$ was considered highly significant.

\section{Results}

Physicochemical characterisation of Co-NPs. The size and morphology of the Co-NPs were characterised by TEM and SEM. The TEM morphology (Fig. 1a) and the SEM morphology (Fig. 1b) of Co-NPs displayed a nearly spherical shape with a mean diameter of about $50 \mathrm{~nm}$. EDS analysis was employed for elemental analysis (the point from Fig. 1b), confirming the presence of Co elements in Co-NPs (Fig. 1c). DLS measurements further confirmed the diameter of Co-NPs with a narrow size distribution (Fig. 1d).

Cytotoxicity of $\mathrm{Co}^{2+}$ and Co-NPs. MTT results demonstrated a time- and dose-dependent cytotoxicity of $\mathrm{Co}^{2+}$ and Co-NPs on BRL-3A cells (Fig. 2). The MTT assay was performed after treating BRL-3A cells with Co-NPs and $\mathrm{Co}^{2+}$ cells cultured in a medium alone as the control group. At the $100 \mu \mathrm{M}$ concentration, co-NPs showed significant toxicity after 24 hours of treatment (Fig. 2). MTT reduction was observed after four hours of exposure to $\mathrm{Co}^{2+}$ and Co-NPs at concentrations of $1 \mu \mathrm{M}, 5 \mu \mathrm{M}$, $10 \mu \mathrm{M}, 50 \mu \mathrm{M}, 100 \mu \mathrm{M}$ and $500 \mu \mathrm{M}$ with reduction of $1.1 \%, 1.8 \%, 3.0 \%, 11.5 \%, 17.1 \%, 41.1 \%$ and $1.7 \%$, $2.7 \%, 7.3 \%, 24.6 \%, 42.5 \%, 45,2 \%$, respectively, with a further reduction to $2.1 \%, 4.5 \%, 6.3 \%, 15.4 \%, 27.6 \%$, 


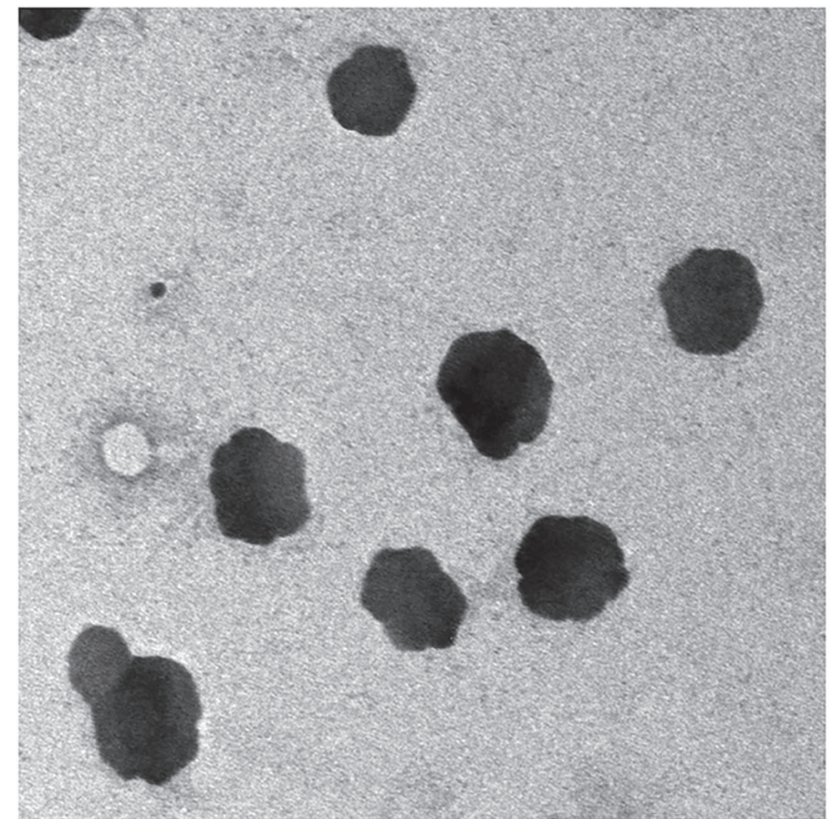

Fig. 1a

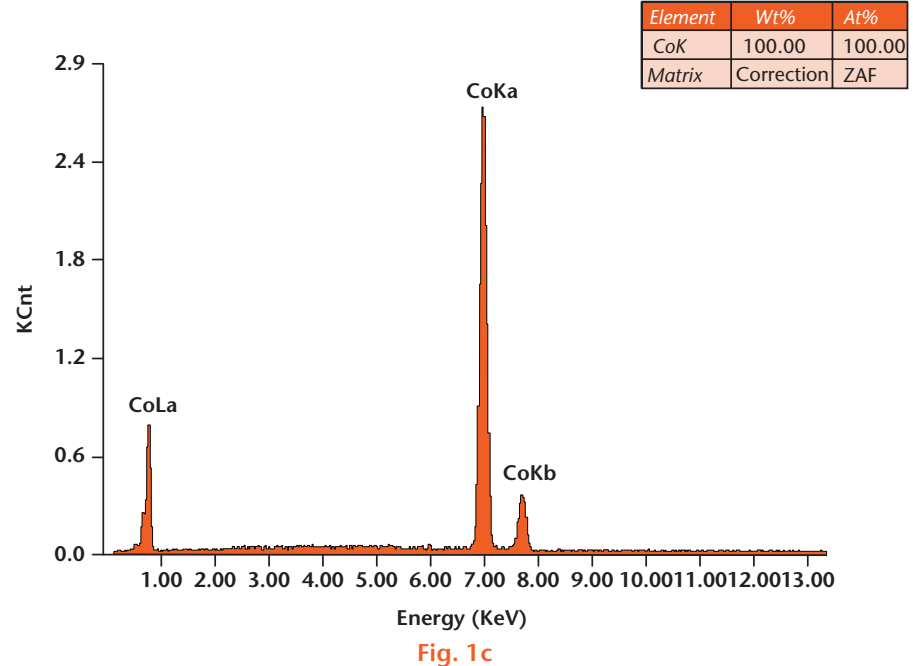

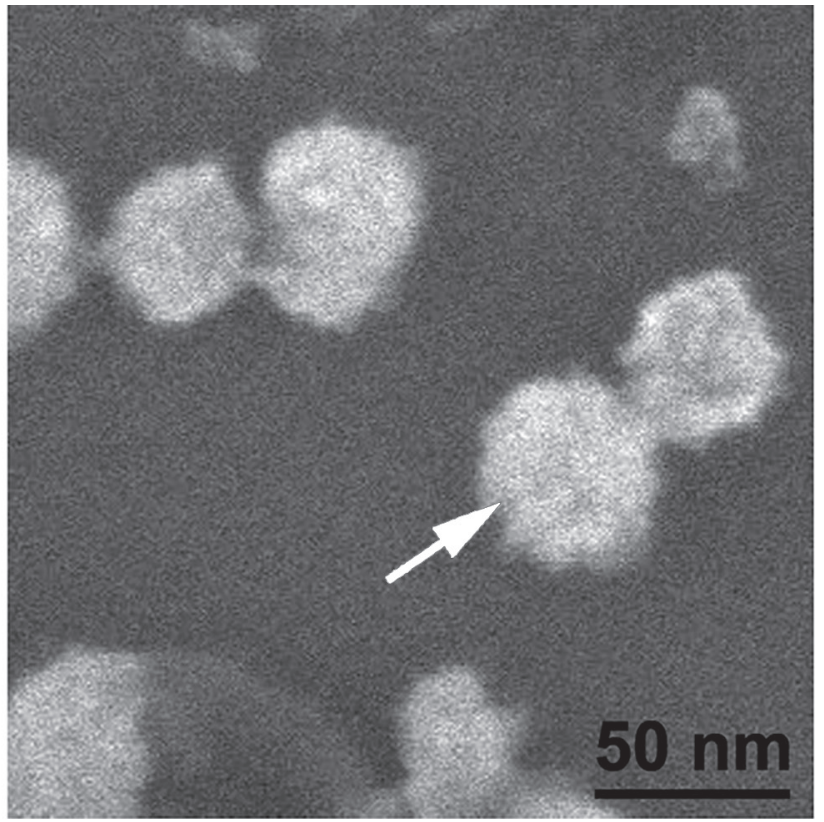

Fig. $1 \mathrm{~b}$

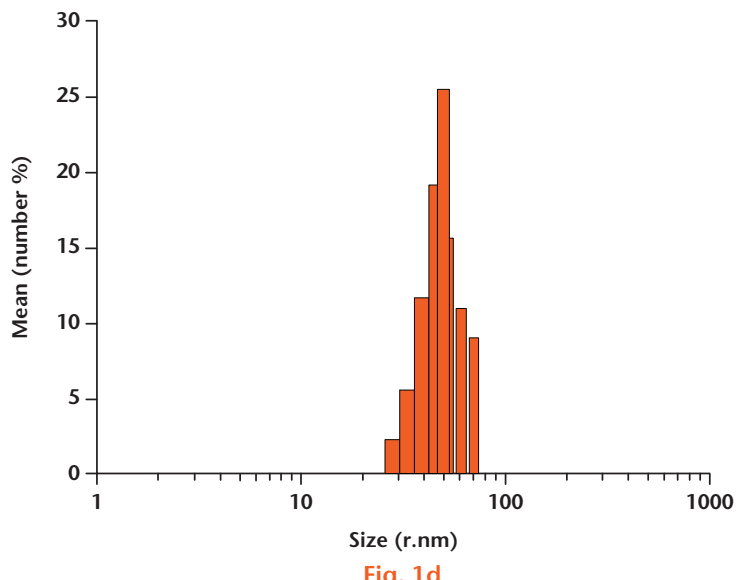

Fig. 1d

Fig. 1

Physicochemical properties of cobalt nanaparticles (Co-NPs). a) TEM micrograph of Co-NPs. Scale bar is $50 \mathrm{~nm}$. b) SEM micrograph of Co-NPs. Scale bar is 50 nm. c) The EDS analysis of Co-NPs (the black arrow marker in b). d) Particle size distribution of Co-NPs.

$52.9 \%$ and $3.7 \%, 5.9 \%, 18.0 \%, 38.1 \%, 56.8 \%, 74.1 \%$ after 24 hours of exposure. After 48 hours of exposure to $\mathrm{Co}^{2+}$ and Co-NPs, MTT reduced to $6.1 \%, 8.3 \%, 11.6 \%$, $35.0 \%, 51.3 \%, 67.4 \%$ and $5.8 \%, 8.7 \%, 34.3 \%, 49.3 \%$, $65.1 \%, 79 \%$, respectively. The half-maximal inhibitory concentration of Co-NPs was $100 \mu \mathrm{M}$ (after 24 hours of incubation).

Apoptosis or necrosis can cause the destruction of the cell membrane structure, leading to cell plasma lactate dehydrogenase ( $\mathrm{LDH})$ release. The cytotoxicity was further confirmed by measuring LDH release levels in cell culture medium with different concentrations of $\mathrm{Co}^{2+}$ or Co-NPs for 24 hours. The result showed that LDH release was significantly induced by Co-NPs (Fig. 3), indicating that Co-NPs could lead to cell membrane damage.

Influence of $\mathrm{Co}^{2+}$ and Co-NPs on ROS production. The ability of $\mathrm{Co}^{2+}$ and Co-NPs to induce oxidative stress was evaluated by measuring the levels of ROS formation in BRL-3A cells (Fig. 4). Results showed that the Co-NPs significantly induced the intracellular production of ROS, compared with $\mathrm{Co}^{2+}$, on normal liver cells after 24 hours of exposure. The levels of ROS were increased 2.17 and 3.84 times in normal liver cells compared with the control group at $10 \mu \mathrm{M}$ and $100 \mu \mathrm{M}$ (data not shown), respectively. No significant induction of cellular ROS production was seen according to different concentrations of $\mathrm{Co}^{2+}$ in this study. 

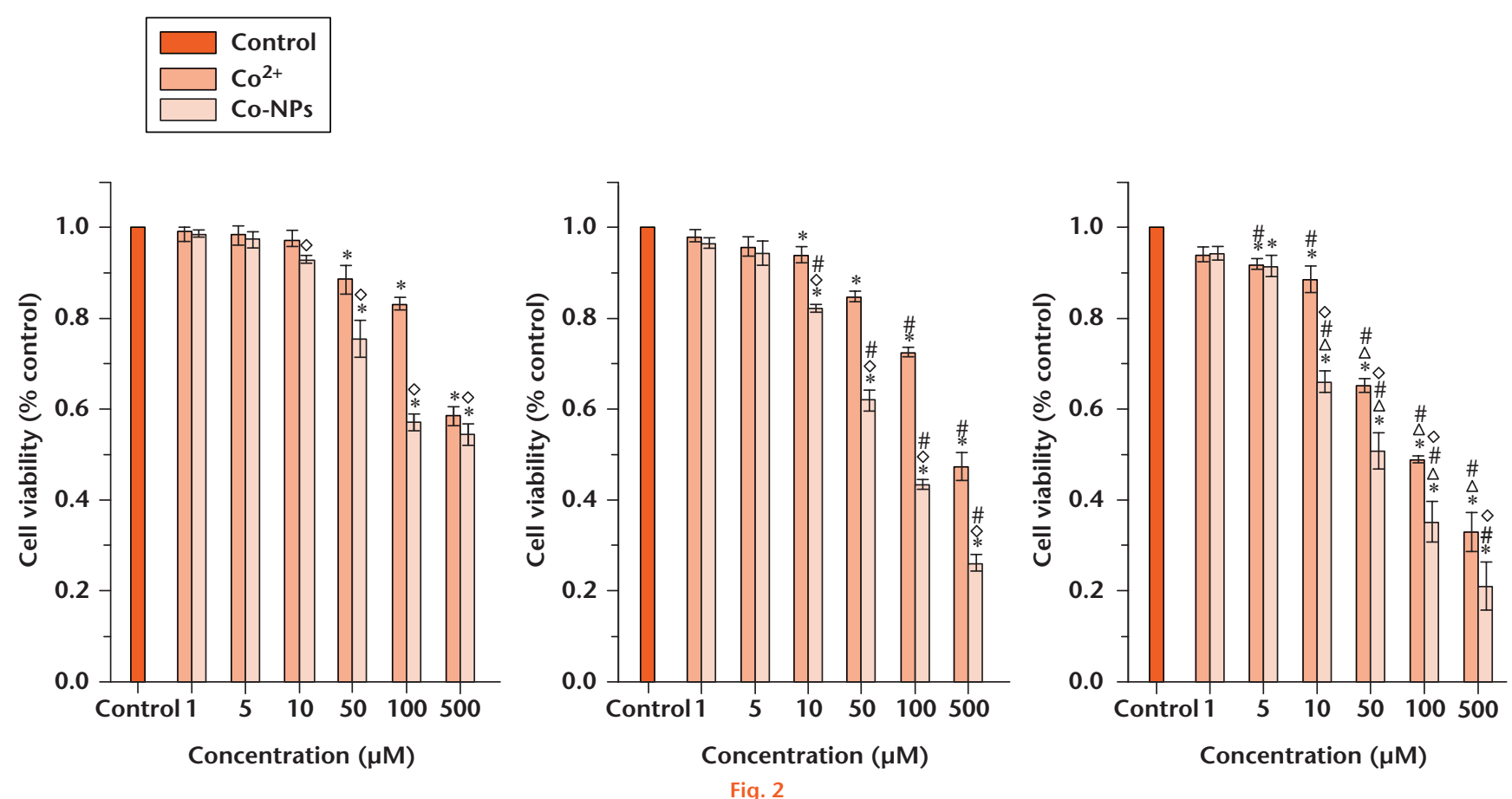

Viability of BRL-3A exposed to cobalt ions $\left(\mathrm{Co}^{2+}\right)$ and cobalt nanoparticles (Co-NPs) was determined by the MTT assay. BRL-3A cells were treated with Co ${ }^{2+}$ $(0-500 \mu \mathrm{M})$ and Co-NPs $(0-500 \mu \mathrm{M})$ for four, 24 and 48 hours (left to right). Co ${ }^{2+}$ and Co-NPs decreased cell viability in time- and dose-dependent manners. All data were expressed as mean and Standard deviation of three independent experiments performed in triplicate. ${ }^{*} p<0.05$ compared with control; $\diamond \mathrm{p}<0.05$ compared with $\mathrm{Co}^{2+} ; \# \mathrm{p}<0.05$ compared with four hours; $\triangle \mathrm{p}<0.05$ compared with 24 hours.

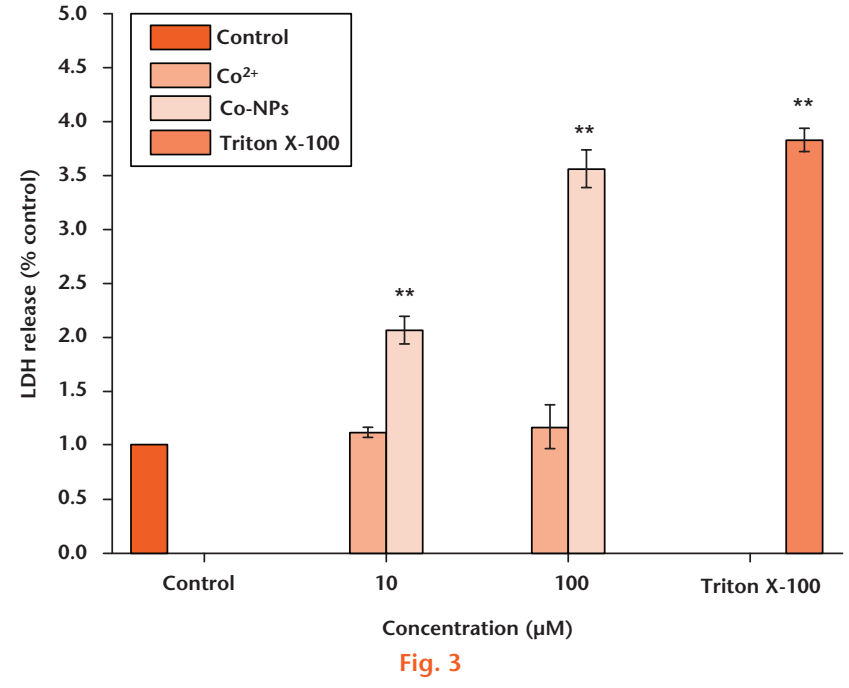

The LDH level of BRL-3A cells incubated with different concentrations of cobalt ions $\left(\mathrm{Co}^{2+}\right)$ and cobalt nanoparticles (Co-NPs) for 24 hours. All data were expressed as mean and standard deviation of three independent experiments performed in triplicate. ${ }^{* *} p<0.01$, compared with the control.

Effects of $\mathrm{Co}^{2+}$ and $\mathrm{Co}-\mathrm{NPs}$ on expression of apoptotic gene mRNA expression in BRL-3A cells. In order to determine if $\mathrm{Co}^{2+}$ or Co-NPs induce apoptosis in BRL-3A cells, the mRNA expression of $\mathrm{BCl}-2$ and Bax were evaluated by quantitative real-time PCR analysis after 24-hour treatment with $\mathrm{Co}^{2+}$ or Co-NPs $(10 \mu \mathrm{M}, 100 \mu \mathrm{M})$. The ratio of $\mathrm{Bax} / \mathrm{Bcl}-2$ expression was determined because its ratio is significant for determining whether a cell underwent apoptosis. $^{29}$ The $\mathrm{Bax} / \mathrm{Bcl}-2$ ratio was increased dose dependently in BRL-3A cells with $\mathrm{Co}^{2+}$ and Co-NPs treatment (Fig. 5).

Effect of $\mathrm{Co}^{2+}$ and Co-NPs on expression of IL-8 mRNA in BRL-3A cells. In this study, the expression of IL-8 mRNA was used to investigate the relationship between the effects induced by $\mathrm{Co}^{2+}$ or Co-NPs and the immune response. Compared with the control group, the expression of IL-8 mRNA significantly increased after treating the cells at concentrations of $10 \mu \mathrm{M}$ and $100 \mu \mathrm{M}$ Co-NPs for 24 hours $(p<0.01)$. After cells were treated with different concentrations of $\mathrm{Co}^{2+}$, the expression of IL-8 mRNA was only increased at high concentrations of $\mathrm{Co}^{2+}(100 \mu \mathrm{M})$ $(p<0.05) ; 10 \mu \mathrm{M} \mathrm{Co}^{2+}$ did not induce a significant increase of IL-8 mRNA expression in BRL-3A cells (Fig. 6).

DNA damage induced by the $\mathbf{C o}^{2+}$ and Co-NPs. The comet assay was carried out to investigate the effect of the exposure of $\mathrm{Co}^{2+}$ and Co-NPs on DNA strand breaks using BRL-3A cells. The nucleus in control cells appeared round (Fig. 7), similar to the low concentration $\mathrm{Co}^{2+}$ groups (10 $\mu \mathrm{M})$, while the other groups showed an increase in DNA breakage (Fig. 7) compared with the control group. The percentage of DNA in comet tail (\% Tail DNA) was used to evaluate DNA damage, which is recognised as informative and reliable in the measurement of DNA damage. ${ }^{30,31} \mathrm{~A}$ large tail was detected in the nucleus of each cell exposed to the Co-NPs groups $(10,100 \mu \mathrm{M})$ (data not shown). The results suggested that the Co-NPs may correlate with DNA damage. 

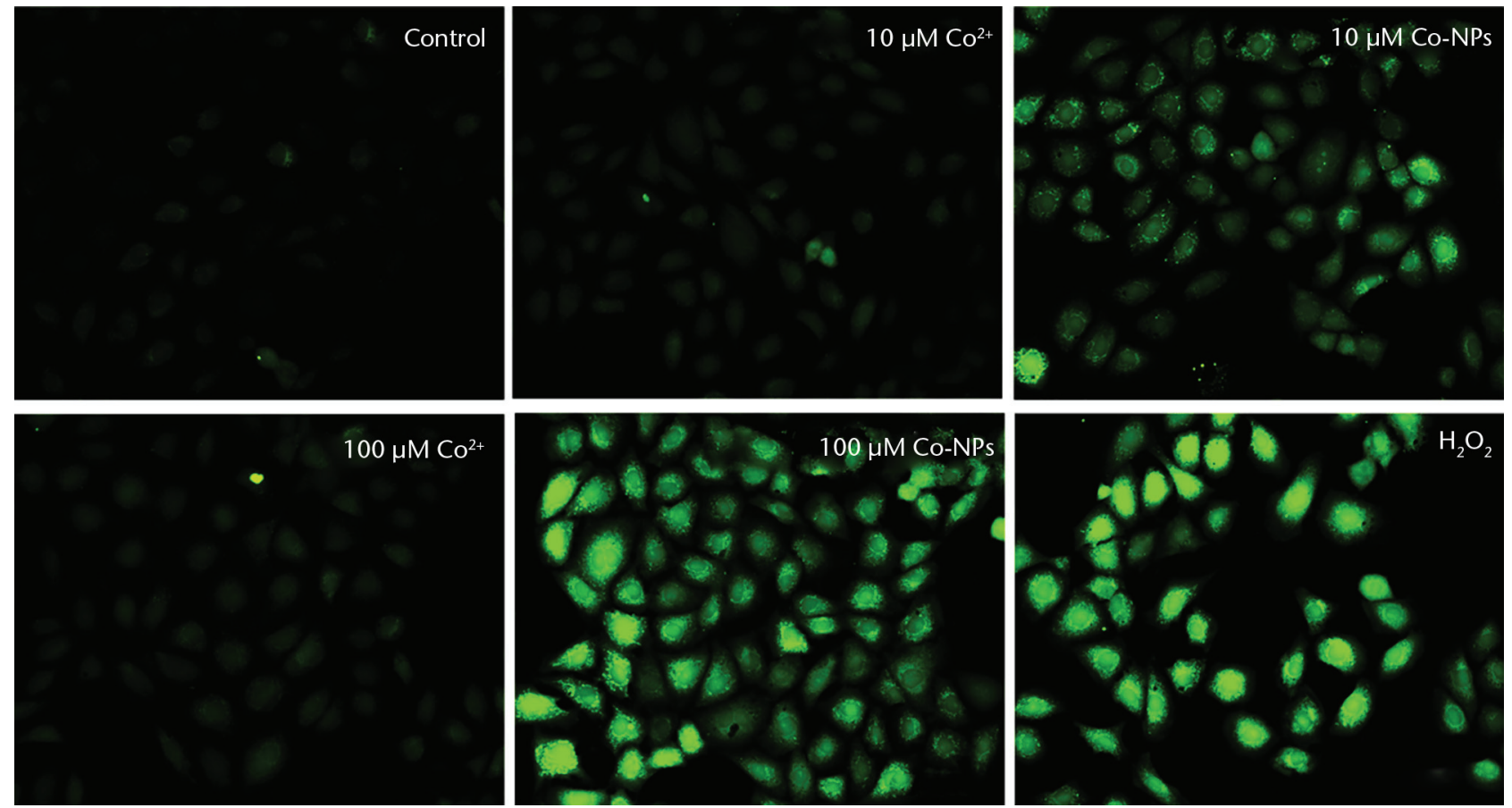

Fig. 4

Fluorescence microscopic picture of BRL-3A cells treated with different concentrations of cobalt ions (Co ${ }^{2+}$ ) or cobalt nanoparticles (Co-NPs) and stained with DCFH-DA; $100 \mathrm{mM} \mathrm{H}_{2} \mathrm{O}_{2}$ was used as a positive control. Scale bar is $100 \mu \mathrm{m}$.

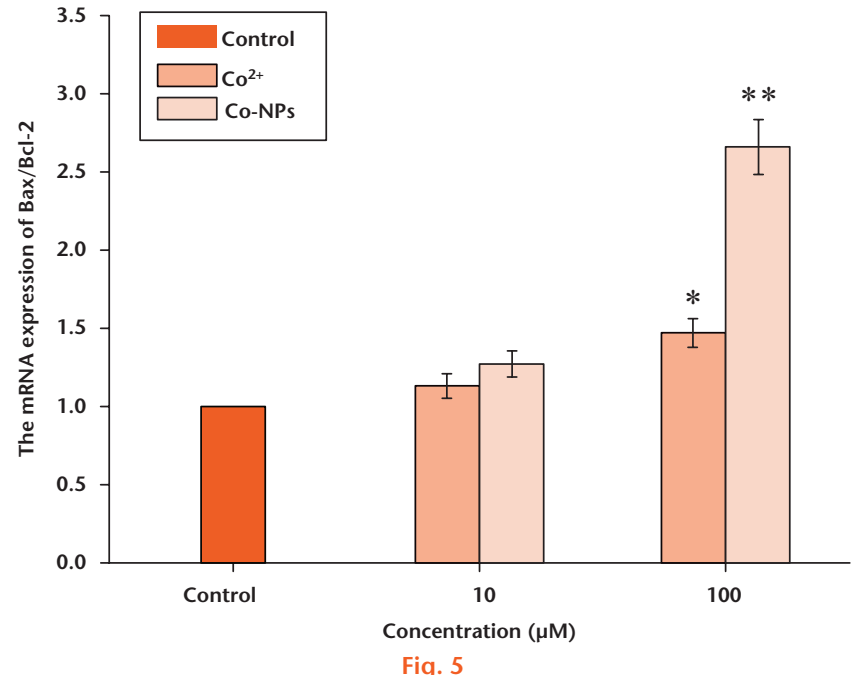

The data were quantified by the ratio of Bax/Bcl-2 mRNA expression. Bax/ $\mathrm{Bcl}-2$ mRNA expression (index for apoptosis status) was only increased after cobalt nanoparticles (Co-NPs) exposed at concentrations of $10 \mu \mathrm{M}$ and 100 $\mu \mathrm{M}$ for 24 hours. All data were expressed as mean and standard deviation of three independent experiments performed in triplicate. ${ }^{*} p<0.05,{ }^{* *} p<0.01$, compared with the control.

\section{Discussion}

With the development of the MoM bearing to THAs, the potential biological adverse effects of degradation products on human tissue has received significant attention. A recent study has demonstrated that $\mathrm{Co}^{2+}$ and Co-NPs induce time- and dose-dependent cytotoxicity. While it was unknown whether the release of $\mathrm{Co}^{2+}$

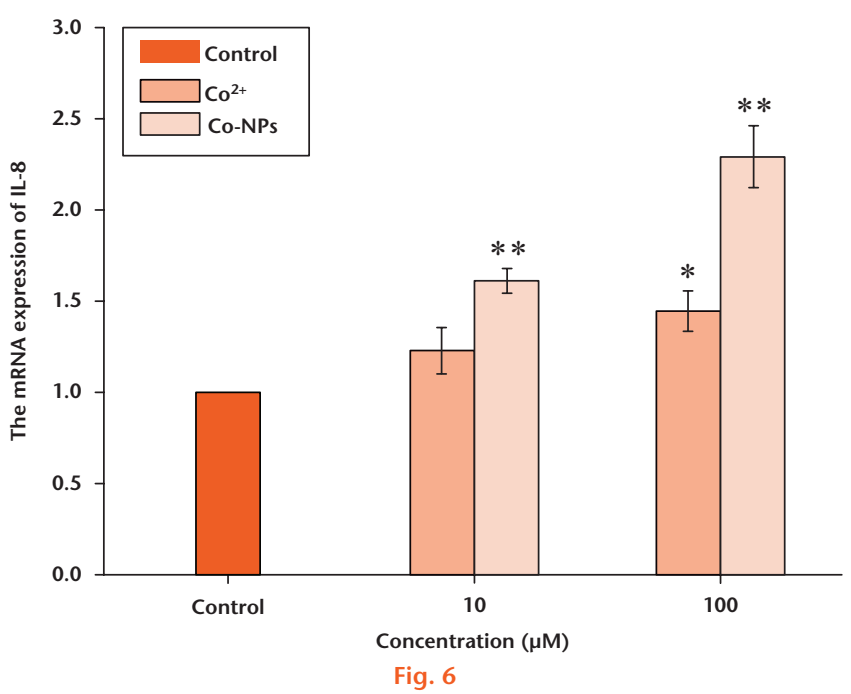

The data were quantified by the ratio of IL- 8 mRNA expression, IL- 8 mRNA expression (index for pro-inflammatory status) was only increased after cobalt ions $\left(\mathrm{CO}^{2+}\right)$ exposed at concentrations of $100 \mu \mathrm{M}$ for 24 hours. All data were expressed as mean and standard deviation of three independent experiments performed in triplicate. ${ }^{*} p<0.05,{ }^{* *} p<0.01$, compared with the control.

originates from the prostheses, or by corrosion of wear particles, the mechanism of $\mathrm{Co}^{2+}$ cytotoxicity is understood in that oxidative stress plays an important role. ${ }^{16-}$ ${ }^{19}$ Young-min Kwon et al ${ }^{23}$ reported the potential toxicity of Co-NPs on macrophages, although $\mathrm{Co}^{2+}$ in the culture medium created by the corrosion of Co-NPs could not induce significant effects. This latter study 

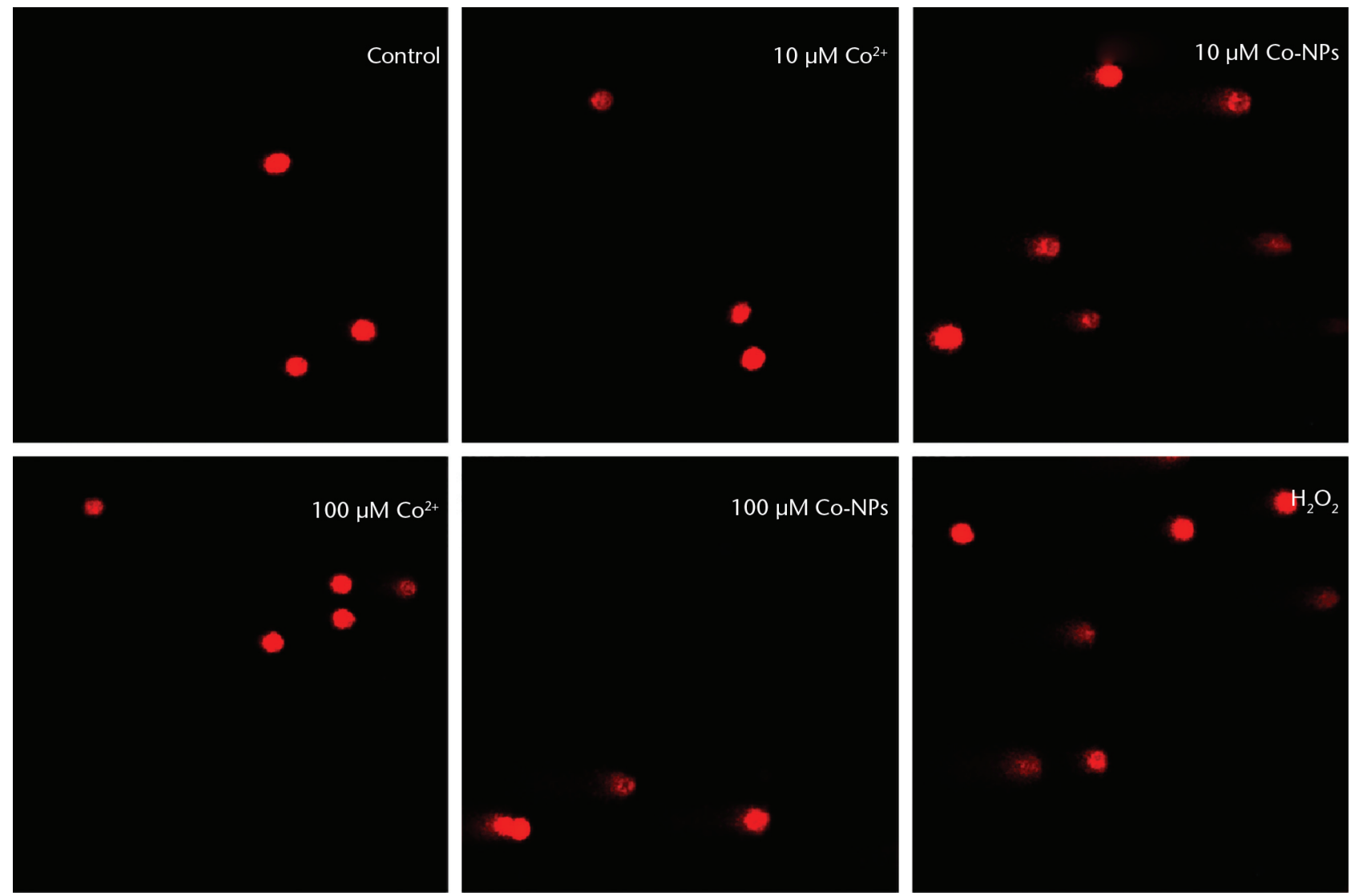

Fig. 7

DNA damage in BRL-3A after 24 hours of exposure to different concentrations of cobalt ions $\left(\mathrm{Co}^{2+}\right)$ or cobalt nanoparticles $(\mathrm{Co}-\mathrm{NPs}) .100 \mathrm{mM} \mathrm{H}_{2} \mathrm{O}_{2}$ was used as a positive control. Scale bar is $50 \mu \mathrm{m}$.

suggested that the cytotoxicity of Co-NPs was more likely to be mediated predominantly by the co-NPs themselves, rather than the metal ions dissolved from the nanoparticles in the extracellular culture medium. Though the toxicity of $\mathrm{Co}^{2+}$ and Co-NPs was confirmed, the specific mechanism was not explained.

In this study, the normal liver cells (BRL-3A cells) were used to assess the biological effects of $\mathrm{CO}^{2+}$ and $\mathrm{Co}-\mathrm{NPs}$. Metal ions dissolved from CoCr-molybdenum (Mo) alloy accumulate in liver and kidney tissue because these organs are known to be involved in the excretion of many metals. Therefore, the kidney and liver are the major target organs for wear debris and metal ions. ${ }^{32}$ Other studies have shown that metal nanoparticles and ions could induce an excessive generation of ROS and cause cell death. ${ }^{33,34}$ Mitochondria are the main source of reactive oxygen species, and the liver cells contain more mitochondria than other cells.

This study indicated that $\mathrm{Co}^{2+}$ and Co-NPs induced a time- and dose-dependent cytotoxic effect on BRL-3A cells and the cytotoxic effects of Co-NPs were stronger than those of $\mathrm{CO}^{2+}$. Our data further confirm that of the previous study on the cytotoxicity of $\mathrm{Co}^{2+}$ and Co-NP exposure to macrophages. ${ }^{23}$ In addition, toxicity was also demonstrated with the release of $\mathrm{LDH}$, implying the effects of Co-NPs on cell membrane integrity. Figure 4 showed that Co-NPs significantly induced the intracellular production of ROS on BRL-3A cells. The finite amounts of ROS could enhance cell proliferation and differentiation, ${ }^{35,36}$ while the excessive amounts of ROS which disturb the oxidant/antioxidant balance could cause oxidative damage to lipids, proteins and DNA. 37,38 The data suggest that Co-NPs induced DNA damage through generation of oxidative stress in BRL-3A cells.

The Bcl-2 family proteins contain anti-apoptotic proteins such as $\mathrm{BCl}-2$ and pro-apoptotic proteins such as Bax, and are the critical regulators of the mitochondrial apoptotic pathway. The $\mathrm{Bcl}-2$ family proteins regulate cytochrome $c$ release from the mitochondria into the cytosol. Bcl-2 proteins inhibit cytochrome c release by protecting permeability transition and stabilising the function of the outer mitochondrial membrane, whereas Bax proteins induce the release of cytochrome $c^{39-41}$. The ratio of the pro-apoptotic and anti-apoptotic $\mathrm{Bcl}-2$ family $(\mathrm{Bax} / \mathrm{BCl}-2)$ is a key indicator of the release of cytochrome $\mathrm{C}$ from the mitochondria into the cytosol. ${ }^{42}$ Figure 5 showed that Co-NPs increased the ratio of $\mathrm{Bax}$ to $\mathrm{Bcl}-2$ levels, and the results suggested that Co-NPs regulate 
the permeability of the outer membrane of mitochondria through $\mathrm{BCl}-2$ family proteins, leading to the release of cytochrome c, and ultimately apoptosis of BRL-3A cells. However, it is interesting that the $\mathrm{Bcl}-2$ family could also regulate the production of ROS. ${ }^{40,41}$ We speculate that this phenomenon occurred in normal amounts of ROS; excessive amounts of ROS would, conversely, inhibit the expression of $\mathrm{BCl}-2$ and improve the expression of Bax.

More importantly, our data show that $\mathrm{Co}^{2+}$ and Co-NPs induced a dose-dependent increase of IL-8. It has been reported that large amounts of lymphocytes and macrophages were observed in periprosthetic soft-tissue

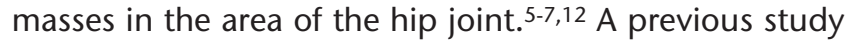
also found a significantly dose-dependent of cobalt oxide nanoparticles increase in pro-inflammatory cytokine TNF$\alpha$ and a decrease in the anti-inflammatory cytokine IL-10.43 Therefore, the results indicate that Co-NPs could induce an inflammatory response in BRL-3A cells.

In conclusion, this study suggests that $\mathrm{Co}^{2+}$ and Co-NPs could induce time- and dose-dependent cytotoxicity and genotoxicity in normal liver cells in vitro. The probable mechanisms of toxicity could be that $\mathrm{Co}^{2+}$ and Co-NPs induce adverse biological effects through the activation of the immune response, the generation of ROS and expression of the Bcl-2 family of proteins. However, there were insufficient data available to explain the relationship between ROS and the Bcl-2 family, and further studies would be necessary to evaluate the relationship between these two systems.

\section{References}

1. MacDonald SJ, McCalden RW, Chess DG, et al. Metal-on-metal versus polyethylene in hip arthroplasty: a randomized clinical trial. Clin Orthop Relat Res 2003;406:282-296.

2. Delaunay C. Second-generation metal bearings in cementless primary total hip arthroplasty: rationale, French homologation and preliminary results. Rev Chir Orthop Reparatrice Appar Mot 2000;86:809-824.

3. Sieber HP, Rieker CB, Köttig P. Analysis of 118 second-generation metal-on-metal retrieved hip implants. J Bone Joint Surg [Br] 1999;81-B:46-50.

4. Doorn PF, Campbell PA, Worrall J, et al. Metal wear particle characterization from metal on metal total hip replacements: transmission electron microscopy study of periprosthetic tissues and isolated particles. J Biomed Mater Res 1998:4:103-111.

5. Park JS, Park YJ, Heo J. Solidification and recycling of incinerator bottom ash through the addition of colloidal silica (SiO2) solution. Waste Manag 2007;27: 1207-1212.

6. Kop AM, Swarts E. Corrosion of a hip stem with a modular neck taper junction: a retrieval study of 16 cases. J Arthroplasty 2009;24:1019-1023.

7. Back DL, Young DA, Shimmin AJ. How do serum cobalt and chromium levels change after metal-on-metal hip resurfacing? Clin Orthop Relat Res 2005;438:177-181.

8. Hart AJ, Sabah S, Henckel J, et al. The painful metal-on-metal hip resurfacing. J Bone Joint Surg [Br] 2009;91-B:738-744.

9. Mabilleau G, Kwon YM, Pandit H, et al. Metal-on-metal hip resurfacing arthroplasty: a review of periprosthetic biological reactions. Acta Orthop 2008;79: 734-747.

10. Mahendra G, Pandit H, Kliskey K, et al. Necrotic and inflammatory changes in metal-on-metal resurfacing hip arthroplasties. Acta Orthop 2009;80:653-659.

11. Ollivere B, Darrah C, Barker T, et al. Early clinical failure of the Birmingham metal-on-metal hip resurfacing is associated with metallosis and soft-tissue necrosis. J Bone Joint Surg [Br]2009;91-B:1025-1030.
12. Pandit H, Glyn-Jones S, McLardy-Smith $\mathbf{P}$, et al. Pseudotumours associated with metal-on-metal hip resurfacings. J Bone Joint Surg [Br]2008;90-B:847-851.

13. Willert HG, Buchhorn GH, Fayyazi A, et al. Metal-on-metal bearings and hypersensitivity in patients with artificial hip joints. A clinical and histomorphological study. J Bone Joint Surg [Am]2005;87-A:28-36.

14. Steens W, von Foerster G, Katzer A. Severe cobalt poisoning with loss of sight after ceramic-metal pairing in a hip-a case report. Acta Orthop 2006;77:830-832.

15. Ikeda T, Takahashi K, Kabata T, et al. Polyneuropathy caused by cobalt-chromium metallosis after total hip replacement. Muscle Nerve 2010;42:140-143.

16. Machado C, Appelbe A, Wood R. Arthroprosthetic cobaltism and cardiomyopathy Heart Lung Circ 2012;21:759-760.

17. Oldenburg $\mathbf{M}$, Wegner $\mathbf{R}$, Baur $\mathbf{X}$. Severe cobalt intoxication due to prosthesis wear in repeated total hip arthroplasty. J Arthroplasty 2009; 24: 825

18. Pelclova D, Sklensky M, Janicek $\mathbf{P}$, et al. Severe cobalt intoxication following hip replacement revision: clinical features and outcome. Clin Toxicol (Phila) 2012;50: 262-265.

19. Rizzetti MC, Liberini P, Zarattini G, et al. Loss of sight and sound. Could it be the hip? Lancet 2009;373:1052.

20. Tower SS. Arthroprosthetic cobaltism: neurological and cardiac manifestations in two patients with metal-on-metal arthroplasty: a case report. J Bone Joint Surg [Am] 2010;92-A:2847-2851.

21. Tower SS. Arthroprosthetic cobaltism associated with metal on metal hip implants. BMJ 2012;344:e430.

22. Milosev I, Remskar M. In vivo production of nanosized metal wear debris formed by tribochemical reaction as confirmed by high-resolution TEM and XPS analyses. J Biomed Mater Res A 2009;91:1100-1110.

23. Kwon YM, Xia Z, Glyn-Jones S, et al. Dose-dependent cytotoxicity of clinically relevant cobalt nanoparticles and ions on macrophages in vitro. Biomed Mater 2009; 4:025018.

24. Colognato R, Bonelli A, Ponti J, et al. Comparative genotoxicity of cobalt nanoparticles and ions on human peripheral leukocytes in vitro. Mutagenesis 2008:23:377-382.

25. Ponti J, Sabbioni E, Munaro B, et al. Genotoxicity and morphological transformation induced by cobalt nanoparticles and cobalt chloride: an in vitro study in Balb/3T3 mouse fibroblasts. Mutagenesis 2009;24:439-445.

26. Dash SK, Ghosh T, Roy S, et al. Zinc sulfide nanoparticles selectively induce cytotoxic and genotoxic effects on leukemic cells: involvement of reactive oxygen species and tumor necrosis factor alpha. J Appl Toxicol 2014;34:1130-1144.

27. Singh NP, McCoy MT, Tice RR, et al. A simple technique for quantitation of low levels of DNA damage in individual cells. Exp Cell Res 1988;17:184-191.

28. Końca K, Lankoff A, Banasik A, et al. A cross-platform public domain PC imageanalysis program for the comet assay. Mutat Res 2003;534:15-20.

29. Ozturk AM, Ergun MA, Demir T, et al. Ketamine is toxic to chondrocyte cell cultures. Bone Joint J 2014;96-B:989-994.

30. Kumaravel TS, Jha AN. Reliable Comet assay measurements for detecting DNA damage induced by ionising radiation and chemicals. Mutat Res 2006;605:7-16.

31. Olive PL, Durand RE. Heterogeneity in DNA damage using the comet assay. Cytometry A 2005;66:1-8.

32. Jakobsen SS, Danscher G, Stoltenberg M, et al. Cobalt-chromium-molybdenum alloy causes metal accumulation and metallothionein up-regulation in rat liver and kidney. Basic Clin Pharmacol Toxicol 2007;101:441-446.

33. Park EJ, Choi J, Park YK, et al. Oxidative stress induced by cerium oxide nanoparticles in cultured BEAS-2B cells. Toxicology 2008;245:90-100.

34. Pulskamp K, Diabaté S, Krug HF. Carbon nanotubes show no sign of acute toxicity but induce intracellular reactive oxygen species in dependence on contaminants. Toxicol Lett 2007;168:58-74.

35. Barrett EG, Johnston C, Oberdörster G, et al. Silica-induced chemokine expression in alveolar type II cells is mediated by TNF-alpha. Am J Physiol 1998;275: L1110-L1119.

36. Barrett WC, DeGnore JP, Keng YF, et al. Roles of superoxide radical anion in signal transduction mediated by reversible regulation of protein-tyrosine phosphatase $1 \mathrm{~B}$. J Biol Chem 1999;274:34543-34546.

37. Perry G, Raina AK, Nunomura A, et al. How important is oxidative damage? Lessons from Alzheimer's disease. Free Radic Biol Med 2000;28:831-834.

38. Lanone S, Rogerieux F, Geys J, et al. Comparative toxicity of 24 manufactured nanoparticles in human alveolar epithelial and macrophage cell lines. Part Fibre Toxicol 2009;6:14. 
39. Howard S, Bottino C, Brooke S, et al. Neuroprotective effects of bcl-2 overexpression in hippocampal cultures: interactions with pathways of oxidative damage. J Neurochem 2002;83:914-923.

40. Gottlieb E, Vander Heiden MG, Thompson CB. Bcl-x(L) prevents the initial decrease in mitochondrial membrane potential and subsequent reactive oxygen species production during tumor necrosis factor alpha-induced apoptosis. Mol Cell Biol 2000;20:5680-5689.

41. Starkov AA, Polster BM, Fiskum G. Regulation of hydrogen peroxide production by brain mitochondria by calcium and Bax. J Neurochem 2002;83:220-228.

42. Lee JH, Choi SH, Baek $\mathbf{M W}$, et al. $\mathrm{CoCl}_{2}$ induces apoptosis through the mitochondria- and death receptor-mediated pathway in the mouse embryonic stem cells. Mol Cell Biochem 2013;379:133-140.

43. Chattopadhyay S, Dash SK, Tripathy S, et al. Toxicity of cobalt oxide nanoparticles to normal cells; an in vitro and in vivo study. Chem Biol Interact 2015;226:58-71.

\section{Funding Statement}

This study was supported by the National Natural Science Foundation of China (Ref. No. 81171743): and the Jiangsu Province Natural Science Foundation of China (No.BK20150399).

Author Contribution

Y. K. Liu: Performed experiment, Analysed and interpreted data, Helped to design the study, Helped to write the paper

X. X. Deng: Designed the study, Writing the paper, Performed experiment, Analysed and interpreted data

- H.L. Yang: Designed the study, Writing the manuscript.

ICMJE conflict of interest

None declared.

c) 2016 Yang et al. This is an open-access article distributed under the terms of the Creative Commons Attributions licence (CC-BY-NC), which permits unrestricted use, distribution, and reproduction in any medium, but not for commercial gain, provided the original author and source are credited. 